\title{
Development and validation of a stability-indicating analytical method for simultaneous determination of drugs employed in canine leishmaniasis treatment
}

\author{
Patrícia Espinosa dos Santos ${ }^{\mathrm{a}}$, Ana Carla Lucca ${ }^{\mathrm{a}}$, Marcos Serrou do Amaral ${ }^{\mathrm{b}}$ and Nájla Mohamad Kassab ${ }^{\mathrm{a}^{*}}$ \\ ${ }^{a}$ Laboratory of Pharmaceutical Technology, Faculty of Pharmaceutical Sciences, Food, and Nutrition, Federal

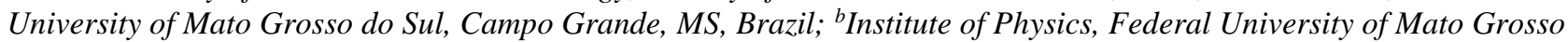 \\ do Sul, Campo Grande, MS, Brazil. \\ *Corresponding author: najla.kassab@ufms.br
}

\begin{abstract}
We developed and validated a stability-indicating method for the simultaneous determination of allopurinol and ketoconazole in the pharmaceutical form of capsules. A Dionex ${ }^{\circledR}$ liquid chromatograph equipped with a diode array detector (DAD) and InertSustain ${ }^{\circledR}$ C18 column $(4.6$ x $100 \mathrm{~mm}$ x $3 \mu \mathrm{m})$ was used and InertSustain ${ }^{\circledR}$ C18 column $(4.6$ x $100 \mathrm{~mm} \times 3 \mu \mathrm{m})$. The chromatographic separation occurred in the isocratic mode with a flow rate of $0.45 \mathrm{~mL} \mathrm{~min}^{-1}$ and mobile phase composed of acetonitrile: water $(52: 48 \mathrm{v} / \mathrm{v})$ with $\mathrm{pH}$ adjusted to 3.0. The wavelengths used were $250 \mathrm{~nm}$ for allopurinol and $225 \mathrm{~nm}$ for ketoconazole. The method was validated by evaluating the parameters of linearity, limits of detection and quantification, precision, accuracy, robustness, and selectivity. The method presented linearity in the concentration ranges of 2.0 to $16.0 \mu \mathrm{g} \mathrm{mL}^{-1}$ for ALLO and 1.0 to $15.0 \mu \mathrm{g} \mathrm{mL}^{-1}$ for KETO. It was precise, with coefficients of variation lower than $2.0 \%$, and accurate, with recovery close to $100.00 \%$. Robustness was indicated by the PlackettBurman model, and the method was not significantly influenced by any of the variations. The selectivity was proven by the purity of the peaks of the drugs close to 1000, in the presence of excipients as degradation of drugs. Therefore the proposed method is simple and fast, with separation for both drugs less than four minutes.
\end{abstract}

Keywords: allopurinol, ketoconazole, canine visceral leishmaniasis, analytical validation, liquid chromatography. https://doi.org/10.22456/2527-2616.102740

\section{Introduction}

Visceral Leishmaniasis (LV) is a chronic disease with high morbidity and mortality rates caused by protozoa of the genus Leishmania. The first case of LV in humans in Brazil was reported in 1934 when the parasite was found after liver necropsy [1-3]. Currently, LV has a worldwide distribution, being endemic in countries of the Americas with $96 \%$ of these notifications in Brazil [4].

The dogs present in the urban transmission cycle as hosts of the parasite establishing fundamental importance in the biological cycle of the disease, act as a natural reservoir and become a source of infection for the sandflies during their repast, helping in the transmission of the disease to humans and other susceptible animals $[5,6]$.

The great interest in the dog is given by the ever-closer relationship with man, both in rural areas and in urban areas, making these animals members of the family, and also by changing the epidemiological profile of the vector. These factors not only provide the essential care already carried out by the owners of these animals, but also generate a greater concern with their health.

The disease control measures indicated are euthanasia of infected animals, vector control, vaccination of animals, and the use of collars and repellents impregnated with deltamethrin [7].Pharmacological therapy is complex because of the greater resistance of canine disease, high toxicity to the animal, and side effects, generating many relapses with little chance of cure. The most commonly used drugs are pentavalent antimonials, amphotericin B, allopurinol, azoles, and some antibiotics. These drugs are used alone or in combination, which makes the treatment more efficient [8].

The combination of allopurinol (ALLO) and ketoconazole (KETO) (Figure 1) has shown therapeutic success.

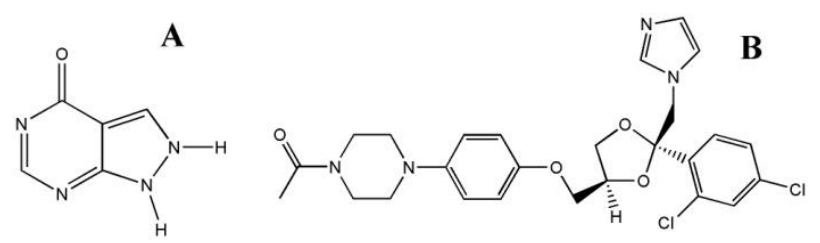

Figure 1. Molecular structure of allopurinol (A) and ketoconazole (B).

ALLO is a drug used to treat gout and acts by blocking the enzyme xanthine oxidase inhibiting the formation of uric acid $[9,10]$. In the parasite, this drug is incorporated into its RNA by blocking the synthesis of proteins essential for its development $[11,12]$.

KETO is an antifungal that inhibits enzyme cytochrome P450 lanosterol-dependent 14-demetilase, which is responsible for transforming lanosterol into ergosterol, an essential component of cell membrane synthesis of microorganisms. In the absence of this component, there is a change in the permeability of this membrane with rupture of the phospholipid chains, consequently, important enzymatic processes for cell growth and replication are interrupted $[13,14]$.

These drugs are administered orally, have low toxicity, low cost and studies report the cure of animals and humans [15-17]. For the treatment of dogs, the doses used 
are: $10 \mathrm{mg} / \mathrm{kg}$, SID, orally, from KETO and 10mg / kg, BID, orally, from ALLO [15].

This association there is no commercial formulation available in drugstores, so it is obtained through manipulation in the form of capsules, which allows adjustment of the dose according to the weight of the animal.

In the literature, no studies are found regarding the quality control of this combination, and it is necessary to develop methods to ensure a safe and quality formulation and consequently an effective treatment.

Thus, the present work had as its purpose the development and validation of an analytical method indicative of stability by the HPLC-DAD technique for simultaneous and quantitative determination of ALLO and KETO drugs in compounded samples, as well as in industrialized samples as a mono drug.

\section{Experimental section}

\section{Reference standards, samples, and reagents}

The standards of allopurinol (purity 100.0\%) and ketoconazole (purity 99.8\%) were obtained from the Brazilian Pharmacopoeia through the Instituto Nacional de Controle de Qualidade e Saúde (INCQS). Compounded samples were obtained from local pharmacies containing ALLO $200 \mathrm{mg}$ and KETO $100 \mathrm{mg}$. Commercial samples were purchased from local drugstores with ALLO $100 \mathrm{mg}$ (batch: 17I153, 08/2019) and KETO $200 \mathrm{mg}$ (batch: 17G766, 06/2019).

HPLC grade solvents were acetonitrile (ACN, SigmaAldrich $^{\circledR}$, JT Baker ${ }^{\circledR}$, Tedia ${ }^{\circledR}$ ), methanol $\left(\right.$ Vetec $\left.^{\circledR}\right)$, ophosphoric acid $\left(\right.$ Synth $^{\circledR}$ ) and ultrapure water (Direct-Q R $3 \mathrm{UV}^{\circledR}$ equipment).

\section{Chromatographic system and conditions}

The method was developed and validated on a Dionex ${ }^{\circledR}$ high-performance liquid chromatograph (Ultimate 3000 model) (Thermo Fisher Scientific, USA), equipped with the Ultimate 3000 RS Variable Wavelength diode array detector (DAD), Ultimate 3000 Pump, connected to a microcomputer with Chromeleon ${ }^{\circledR} 7.1$ software Chromatography Data System.

The chromatographic separation occurred in the isocratic mode with $0.45 \mathrm{~mL} \mathrm{~min}^{-1}$ flow and injection volume was $20 \mu \mathrm{L}$ using InertSustain ${ }^{\circledR} \mathrm{C} 18$ column $(4.6 \times 100 \mathrm{~mm}$ and $3 \mu \mathrm{m}$ particle size) from the manufacturer GL Sciences.

The mobile phase was composed of acetonitrile and acid water $(52: 48 \mathrm{v} / \mathrm{v})$ with $\mathrm{pH}$ adjusted to 3.0 with ophosphoric acid. The wavelengths used were $250 \mathrm{~nm}$ for ALLO and $225 \mathrm{~nm}$ for KETO.

\section{Development and optimization of the analytical method}

Three chromatographic columns were tested: InertSustain ${ }^{\circledR}$ C18 GL Sciences (4.6 x $100 \mathrm{~mm}$ x $\left.3 \mu \mathrm{m}\right)$, Kinetex ${ }^{\circledR}$ C18 Phenomenex (4.6 x $100 \mathrm{~mm}$ x $\left.2.6 \mu \mathrm{m}\right)$ and Discovery ${ }^{\circledR}$ HS C18 Sigma-Aldrich (4.6 x 100 mm x 5 $\mu \mathrm{m})$. The mobile phases tested were methanol and water without adjustment of $\mathrm{pH}$, acetonitrile, and water without adjustment of $\mathrm{pH}$ and acetonitrile and water with $\mathrm{pH} 3$, adjusted with o-phosphoric acid, in different proportions. The choice of the best chromatographic condition was made through the evaluation of the parameters: retention time, peak purity, number of theoretical plates, resolution factors and asymmetry, according to recommendations of the International Conference on Harmonisation [18]

\section{Validation of the analytical method}

The method was validated based on the International Conference on Harmonization [18] and the Association of Official Analytical Chemists International [19] guidelines, following the parameters of linearity, detection limit, quantification limit, accuracy, robustness, and selectivity.

\section{Selectivity}

This parameter was assessed by analyzing the placebo solution, prepared with excipients used in manipulated samples (stearate magnesium, aerosil, sodium lauryl sulfate, premium talc, and corn starch). [20].

The degradation study was carried out with solutions prepared with $20 \mathrm{mg}$ of the standard powder of each medication in acetonitrile:water $(52: 48 \mathrm{v} / \mathrm{v})$, which were placed in direct contact with the degrading agent. For comparison, ALLO and KETO control solutions were prepared without the addition of adegrading agent.

For the percentage of degradation, the range of 10 to $30 \%$ of the content loss of the main peak was considered in relation to the control [21]. The results were evaluated by the retention time, peak purity, and spectral profile in the UV region.

The acid condition was performed using a 1 M hydrochloric acid solution with 30 minutes exposure in a water bath at $60^{\circ} \mathrm{C}$.

The basic condition was performed differently for the two drugs. For ALLO a solution of $1 \mathrm{M}$ sodium hydroxide with 30 minutes exposure in a water bath $60{ }^{\circ} \mathrm{C}$ was used, and for KETO a solution of $0.01 \mathrm{M}$ sodium hydroxide for 10 minutes in a water bath $60{ }^{\circ} \mathrm{C}$ was used.

The oxidative condition was performed with a $0.3 \%$ hydrogen peroxide solution with 30 minutes exposure in a water bath $60{ }^{\circ} \mathrm{C}$.

The photolytic and thermal conditions were performed with $24 \mathrm{~h}$ exposure in a UVB chamber and a stove at 80 ${ }^{\circ} \mathrm{C}$, respectively.

After the exposure time, aliquots of the solutions were removed and diluted and injected under the conditions in the proposed method.

\section{Linearity}

This parameter was evaluated through the construction of analytical curves.

Solutions of the mobile phase diluted standards were prepared considering six concentrations for ALLO (2.0, 
Drug Anal. Res., v. 4, n. 2, p. 24-30, 2020

4.0, 6.0, 10.0, 12.0, and 16.0 $\mu \mathrm{g} \mathrm{mL}^{-1}$ ) and six for KETO (1.0, 3.0, 6.0, 9.0, 12.0, and $\left.15.0 \mu \mathrm{g} \mathrm{mL} \mathrm{mL}^{-1}\right)$. The determinations were performed in triplicate and the results were submitted to linear regression analysis and statistical analysis by analysis of variance (ANOVA).

\section{Precision}

Precision was assessed using repeatability and intermediate precision using commercial sample solutions. Repeatability was confirmed by analyzing six determinations of solutions at concentrations of 5.0 and $10.0 \mu \mathrm{g} \mathrm{mL}^{-1}$ for KETO and ALLO, respectively. The injections were performed on the same day, under the same chromatographic conditions and by the same analyst. Intermediate precision was assessed by two different analysts in six times, on three different days, at the concentrations mentioned above. From the results obtained, standard deviation (SD) and relative standard deviation (RSD) were calculated.

\section{Accuracy}

Accuracy was evaluated through standard recovery assays at three concentration levels. Solutions of the compounded sample were added with known amounts of the standard solution of the drugs, totalizing concentrations of 3.0, 5.0, and $7.0 \mu \mathrm{g} \mathrm{mL}^{-1}$ for KETO and 6.0, 10.0, and $14.0 \mu \mathrm{g} \mathrm{mL}^{-1}$ for ALLO. All determinations were performed in triplicate and percentages of recoveries of each drug were calculated according to AOAC [19].

\section{Limit of detection (LOD) and limit of quantification $(L O Q)$}

The limits were determined by the mathematical relationship between the standard deviation of the intercept with the $\mathrm{Y}$-axis (SD), and the slope of the calibration curve (a), being $3.3 \times(\mathrm{SD} / \mathrm{a})$ and $10 \times(\mathrm{SD} / \mathrm{a})$, respectively.

\section{Robustness}

The robustness was demonstrated by the Plackett-Burman factorial model for 15 experiments and 7 factors that vary between normal (0), major (1), and minor (-1) conditions [22] (Table 1). In order to determine the influence of each factor, solutions of the standards were prepared in the concentrations of $10 \mu \mathrm{g} \mathrm{mL}^{-1}$ of ALLO and $5 \mu \mathrm{g} \mathrm{mL}^{-1}$ of KETO and the determinations made in triplicate. The effect produced by each factor was calculated by the difference of the results obtained with the normal condition in relation to the variant conditions [23]. For the method to be considered robust the effect produced must be less than the critical value.
Table 1. Variable factors and conditions for the robustness test.

\begin{tabular}{|c|c|c|c|c|c|}
\hline Factors & Unit & Limit & $\begin{array}{c}\text { Variable } \\
\text { condition } \\
(-1) \\
\end{array}$ & $\begin{array}{c}\text { Variable } \\
\text { condition } \\
(0)\end{array}$ & $\begin{array}{c}\text { Variable } \\
\text { condition } \\
(+1)\end{array}$ \\
\hline $\begin{array}{l}\text { A - mobile } \\
\text { phase } \mathrm{pH}\end{array}$ & --- & $\pm 0,2$ & 2,8 & 3,0 & 3,2 \\
\hline $\begin{array}{l}\mathrm{B}-\text { proportion } \\
\text { of mobile phase }\end{array}$ & $\%$ & \pm 2 & $50: 50$ & $52: 48$ & $54: 46$ \\
\hline C - wavelength & $\mathrm{nm}$ & \pm 2 & $223 / 248$ & $225 / 250$ & $227 / 252$ \\
\hline $\begin{array}{l}\mathrm{D} \text { - sonication } \\
\text { time }\end{array}$ & $\min$ & \pm 2 & 8 & 10 & 12 \\
\hline $\begin{array}{l}\mathrm{E}-\text { room } \\
\text { temperature }\end{array}$ & ${ }^{\circ} \mathrm{C}$ & \pm 2 & 23 & 25 & 27 \\
\hline $\begin{array}{l}\text { F- acetonitrile } \\
\text { brand }\end{array}$ & --- & --- & Tedia & $\begin{array}{l}\text { Sigma- } \\
\text { Aldrich }\end{array}$ & JT Baker \\
\hline $\begin{array}{l}\mathrm{G}-\text { mobile } \\
\text { phaseflow }\end{array}$ & $\begin{array}{c}\mathrm{mL} \\
\min ^{-1}\end{array}$ & $\begin{array}{c} \pm 0,0 \\
2\end{array}$ & 0,43 & 0,45 & 0,47 \\
\hline
\end{tabular}

\section{Application of the analytical method}

The developed method was used to quantify ALLO and KETO in compounded samples of the drugs associated with $200 \mathrm{mg}$ of ALLO and $100 \mathrm{mg}$ of KETO and in commercial samples in tablet of the drugs in monodrugs being ALLO $100 \mathrm{mg}$ and KETO $200 \mathrm{mg}$.

\section{Results and Discussion}

\section{Method optimization}

In the mobile phases composed of acetonitrile:water and methanol:water, both without $\mathrm{pH}$ adjustment, the separation of the chromatographic peaks in the tested columns was not obtained.

The mobile phase of acetonitrile and water at $\mathrm{pH} 3.0$ showed good separation by increasing the concentration of acetonitrile, reaching the optimum ratio of 52:48 v/v.

The Sigma-Aldrich column presented parameters of resolution and asymmetry out of the recommended and thus discarded.

The Phenomenex and GL Sciences columns were those that showed separation of the compounds and parameters within the recommended, however, the GL Sciences column obtained superior performance with lower run time, better separation of the chromatographic peaks, and higher resolution parameters, plates and peak purity (Figure 2).

Thus the chromatographic conditions chosen were InertSustain ${ }^{\circledR}$ C18 column from the manufacturer GL Sciences ( 4.6 × $100 \mathrm{~mm}$ x $3 \mu \mathrm{m})$; mobile phase consisting of acetonitrile and acidic water with $\mathrm{pH}$ adjusted to 3.0 using o-phosphoric acid (52:48 v/v); flow rate of $0.45 \mathrm{~mL}$ $\min ^{-1}$. 


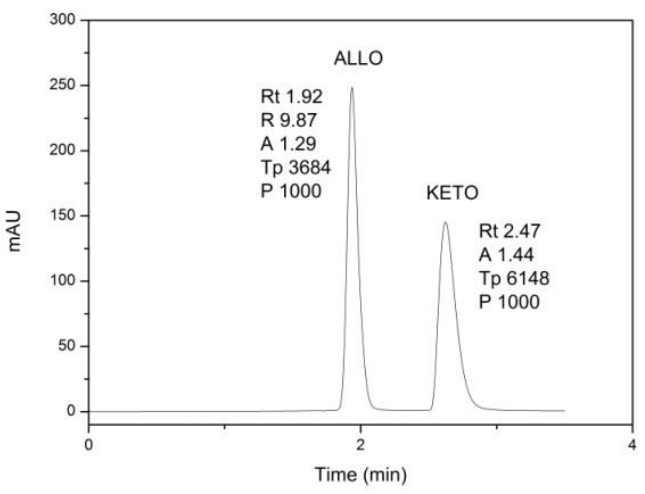

Figure 2. Chromatogram of ALLO (allopurinol) and KETO (ketoconazole) obtained with the InertSustain ${ }^{\circledR}$ C18 GL Sciences $(4.6 \times 100 \mathrm{~mm} \times 3 \mu \mathrm{m})$ column using a mobile phase composed of acetonitrile:water $(52: 48 \mathrm{v} / \mathrm{v}) \mathrm{pH} 3.0$ adjusted with

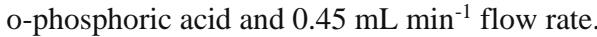

\section{Validation of the analytical method}

\section{Selectivity}

In the placebo analysis, no peak was observed in drug retention times, indicating the selectivity of the method. The forced degradation study was evaluated through peak purity (> 950) and percent degradation (10-30\%). The control solution presented levels of $99.30 \pm 0.25 \%$ for ALLO and $101.61 \pm 0.12 \%$ for KETO, peak purities were 1000 for both drugs. The acid condition presented degradation of $13.15 \%$ for ALLO and $27.11 \%$ for KETO, the peak purity index higher than 950 . In the degradation of KETO (Figure 3) a peak in retention time and spectral profile different from that of the drug indicating to be a degradation product.
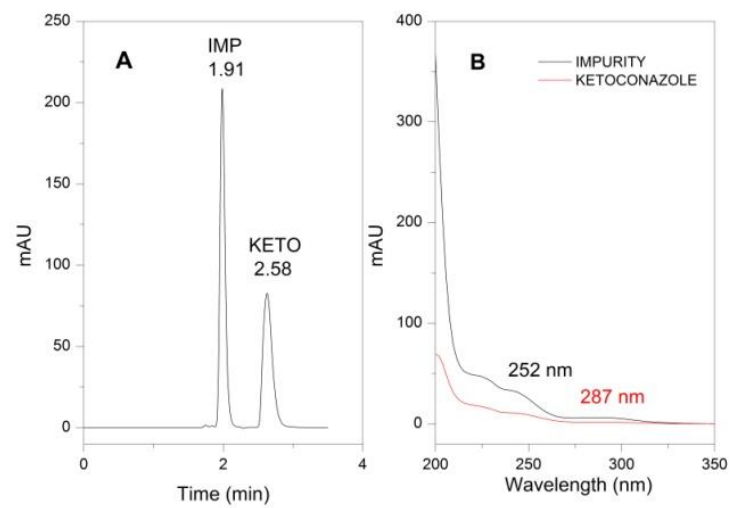

Figure 3. Chromatogram of KETO (ketoconazole) after acid stress (A). Spectrum in the ultraviolet region of impurity (IMP) $1.91 \mathrm{~min}$ and KETO $2.58 \mathrm{~min}$, resulting from acid stress (B).

In the basic condition of ALLO, a degradation of $10.84 \%$ with a purity greater than 950 was obtained. In the condition used for KETO, the degradation value was $64.88 \%$, indicating a great sensitivity of the drug for this condition.

In the oxidative condition, the degradation was $29.60 \%$ for ALLO and $18.93 \%$ for KETO, peak purities were greater than 950. A peak in time 1.99 was observed in the KETO chromatogram not corresponding to the drug and can be observed in the images of its spectra, featuring drug degradation product (Figure 4).

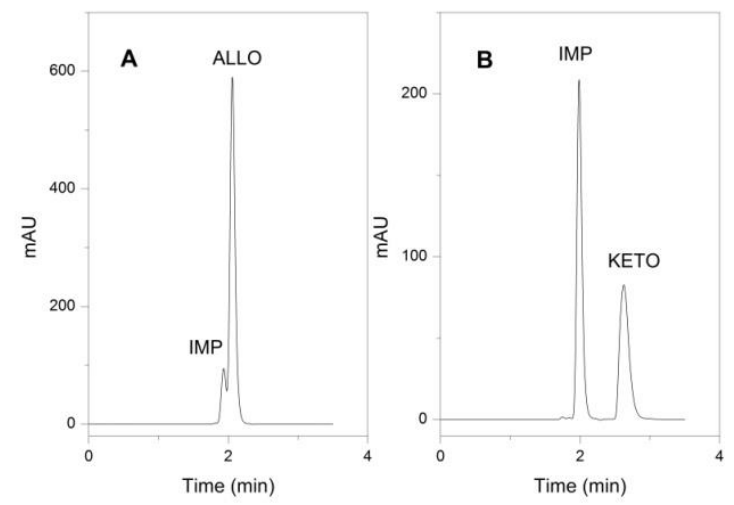

Figure 4. Chromatogram of ALLO (allopurinol) (A) and KETO (ketoconazole) (B) after oxidative stress.

In the thermal and photolytic conditions, there was no degradation of the drugs, indicating greater stability for these media, the peak purities were greater than 950 . Singh and Gadhawala (2013) performed a study of ALLO degradation observing greater sensitivity in the oxidative medium with the formation of drug degradation product. Similarly, the researcher verified the greater stability of the drug in the photolytic and thermal medium [24].

Sajan et al. (2014) observed significant degradation of ALLO in acidic, basic, and photolytic medium with the formation of drug degradation products [25].

Tian et al. (2016) observed higher sensitivity of KETO in the oxidative medium [26]. However, the study of Mhaske and Sahasrabudhe (2011) showed great degradation of KETO in the acidic, basic, and oxidative medium with formation of degradation products of the drug, and greater stability in photolytic and thermal media [27].

Studies related to the photostability of KETO in formulations demonstrate its instability against this medium with the formation of drug degradation products. These studies work with semisolid formulations of the drug, usually shampoos and emulsions, providing an environment more conducive to its degradation against UV light and other degradation media, differently in this study using the solid-state drug itself (powder) in direct contact with the light [28-31].

\section{Linearity, limit of detection and limit of quantification}

The linearity of the method was demonstrated with correlation coefficients of 0.9995 for ALLO and 0.9999 for KETO, the regression equations obtained were $\mathrm{y}=$ $2.9421 \mathrm{x}+0.2436$ and $\mathrm{y}=4.0947 \mathrm{x}+0.0930$, respectively. The ANOVA test showed that linear regression has significance, where calculated $\mathrm{F}$ was greater than $\mathrm{F}$ critical for ALLO.

The inverse occurred for KETO indicating that another model could better explain the data, but does not mean 
that the model in question has no significance because by the value of $r^{2}$ it is possible to state that $99.987 \%$ of the variance is explained by the mathematical model.

The correlation between the analyte concentration and the equipment signal was also demonstrated by the Regression Residue analysis. Residual is defined as the difference between the values observed and the values estimated by the regression. In Figure 5 it is possible to visualize that the residues are distributed heterogeneously and randomly around the axis, indicating that there is no tendency.

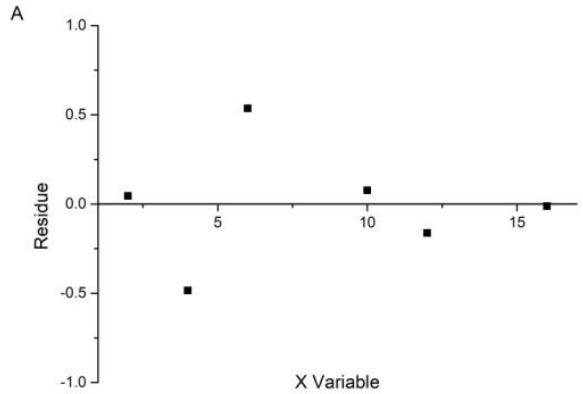

B

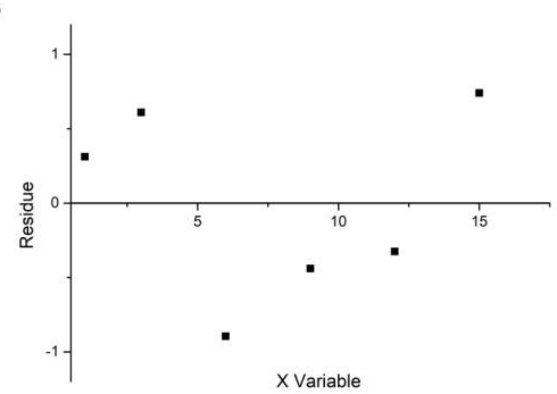

Figure 5. Analyzes of the residuals of the calibration analytical curves of allopurinol (A) and ketoconazole (B).

The LOD obtained were 0.0858 and $0.2599 \mu \mathrm{g} \mathrm{mL}^{-1}$ for ALLO and KETO, respectively. The LOQ was 0.0331 and $0.1004 \mu \mathrm{g} \mathrm{mL}^{-1}$ for ALLO and KETO, respectively.

\section{Precision}

The RSD values for ALLO and KETO were 0.21 and $0.24 \%$, respectively, for the intermediate precision. For repeatability, 0.11 and $0.10 \%$ were obtained for ALLO and KETO, respectively. All values are within the recommended maximum limit of $2.0 \%$ [18].

\section{Accuracy}

The recovery values and the RSD obtained were $100.77 \pm$ $0.93 \%$ for ALLO and $100.16 \pm 0.30 \%$ for KETO. The results are in agreement with the acceptable limit range of $98.0-102.0 \%$ [19].

\section{Robustness}

The critical values calculated for ALLO and KETO were 1.8609 and 2.7350, respectively, for the major levels $(+1)$, and 3.67676 and 1.1819 , respectively, for the minor levels $(-1)$. The results of the effects produced (Table 2) indicate that small variations in the conditions tested do not significantly alter the proposed method.

Table 2. Results of the effects produced by each factor in the major and minor conditions in relation to the normal condition.

\begin{tabular}{ccccc}
\hline \multirow{2}{*}{ Factors } & \multicolumn{2}{c}{ Allopurinol } & \multicolumn{2}{c}{ Ketoconazole } \\
\cline { 2 - 5 } & $\mathbf{( + 1 )}$ & $\mathbf{( - 1 )}$ & $\mathbf{( + 1 )}$ & $\mathbf{( - 1 )}$ \\
\hline A & $-0,3203$ & 0,3810 & 0,4817 & 0,3325 \\
B & $-1,4595$ & $-1,3318$ & $-1,2727$ & $-0,3425$ \\
C & 1,6002 & $-1,2911$ & 0,0502 & $-0,6800$ \\
D & $-0,0863$ & 0,2071 & $-1,8559$ & 0,8175 \\
E & $-0,2446$ & $-0,1452$ & $-1,1427$ & $-0,2075$ \\
F & 0,1746 & 0,5015 & $-1,0592$ & 0,4475 \\
G & 1,1838 & $-1,0234$ & 1,2168 & 0,3250 \\
\hline
\end{tabular}

\section{Application of the analytical method}

Three manipulated samples of the association were analyzed, the average result of the content obtained in sample 1 was $101.28 \pm 0.34 \%$ for ALLO and $102.35 \pm$ $0.25 \%$ for KETO, in sample 2 it was $103.06 \pm 0.13 \%$ for ALLO and $103.56 \pm 0.23 \%$ for KETO, and in sample 3 it was $104.67 \pm 0.42 \%$ for ALLO and $100.66 \pm 0.15 \%$ for KETO. In the commercial samples available separately from the drugs, the contents of $104.70 \pm 0.14 \%$ for ALLO and $104.02 \pm 0.11 \%$ for KETO were obtained.

\section{Conclusions}

A stability-indicating HPLC-DAD method was developed and validated for the simultaneous determination of ALLO and KETO. This method proved to be selective, precise, accurate, linear, and robust. The method also showed good results in the quantification of drugs in other types of industrialized solid formulations, such as tablets. In addition to being a fast methodology and making use of low-cost solvents and can be inserted into the routine of drug quality control laboratories.

\section{Acknowledgments}

This work was carried out with support from the Federal University of Mato Grosso do Sul - UFMS/MEC - Brazil, the Coordenação de Aperfeiçoamento de Pessoal de Nível Superior - Brazil (CAPES) - Finance Code 001, and the National Council for Scientific and Technological Development (CNPq-Brazil).

\section{Conflict of interest}

The authors declare no conflicts of interest.

\section{References}

1. Almeida PS, MinzãoER,MinzãoLD,Silva SR, Ferreira AD, Faccenda O, Filho JDA. Aspectos ecológicos de flebotomíneos (Diptera: Psycodidae) em área urbana no município de Ponta Porã, estado de Mato Grosso do Sul. 
Rev. da Soc. Brasil. de Med. Tropical. 2010, 43(6): 723 727.

2. Silva FS. Patologia e patogênese da leishmaniose visceral canina. R Trópica Ci Agrárias Bio. 2007, 1(1): 20-31.

3. Gontijo CMF, Melo MN. Leishmaniose Visceral no Brasil: quadro atual, desafios e perspectivas. $\mathrm{R}$ Brasileira de Epidemiologia.2004, 7(3).

4. WHO. World Health Organization. Leishmaniasis: Brazil - Leishmaniasis Country Profiles. Available from:

https://www.who.int/leishmaniasis/burden/Leishmania sis_Brazil/en/. 2020.

5. Fontes SD, Silva ASA. Leishmaniose visceral canina. Anais SIMPAC. 2011, 3(1): 285-290.

6. Krauspenhar C, Beck C, Sperotto V, Silva AA; Bastos, $\mathrm{R}$; Rodrigues, L. Leishmaniose visceral em um canino de Cruz Alta, Rio Grande do Sul, Brasil. Ciência Rural. 2007, 37(3): 907-910.

7. Furlan MBG. Epidemia de leishmaniose visceral no Município de Campo Grande-MS, 2002 a 2006. Epidemiologia e Serviços de Saúde.2010, 19(1): 15-24.

8. Schimming BC, Pinto e Silva JRC. Leishmaniose visceral canina - Revisão de literatura. R Ci Elet Med Vet.2012, 19.

9. Godoy ALPC, Jesus C, Oliveira ML, Rocha A, Pereira MPM, Laranjeira DF, Lanchote VL, Barrouin-Melo SM. Determination of allopurinol and oxypurinol in dogs plasma by high-performance liquid chromatography with an ultraviolet detector: application for pharmacokinetic studies. J Chromatography.2017, 8(4).

10. Fatatry HMEL, Osman WM. Development and validation of different chromatographic methods for determination of two hypouricemic drugs in their combined dosage form. Inter $\mathbf{J}$ Adv Research Chem Sci. 2014, 1(7):47-56.

11. Reguera MRM, Morán M, Pérez-Pertejo Y, GarcíaEstrada C. Current status os prevention and treatment of canine leishmaniasis. Vet Parasit. 2016, 227:98-114.

12. Ginel PJ, Lucena R, López R, Molleda JM. Use of allopurinol for maintenance of remission in dogs with leishmaniasis. J Small Animal Practice. 1998, 39:271274.

13. Kumar S, Nanda RK, Kuttepali P, SharmaSK. Development and validation of reverse-phase HPLC method for estimation of hamycin and ketoconazole in pharmaceutical cream. Inter J PharmaSci Research. 2014, 5(1):263-268.

14. Amrutiya N, Madan M, Bajaj A. Development and validation of RP-HPLC method for simultaneous estimation of prednicarbate, mupirocin and ketoconazole in topical dosage forms. $\mathrm{J}$ Anal Chem.2010, 65(11): 1148-1154.

15. Nery G, Becerra DRD, Borja LS, Magalhães-Junior JT, Souza BMPS, Franke CR, Veras PST, Laranjeira DF, Barrouin-Melo SM. Avaliação da infectividade parasitária a Lutzomyialongipalpis por xenodiagnóstico em cães tratados para leishmaniose visceral naturalmente adquirida. PesqVet Bras.2017, 37(7): 701-707.

16. Kuyucu NMD, Kara CMD, Bakirtaç AMD, Teziç TMD. Successful treatment of visceral leishmaniasis with allopurinol plus ketoconazole in an infant who developed pancreatitis caused by meglumineantimoniate. Pediatric Infec Disease J.2001, 20(4):455-457.

17. Halim MA, Alfurayh O, Kalin ME, Dammas S, AlElisa, A, Damanhouri G. Successful treatment of visceral leishmaniasis with allopurinol plus ketoconazole in a renal transplant recipient after the occurrence of pancreatitis due to stibogluconate. ClinInfec Diseases, 1993, 16:397-399.

18. International Conference on Harmonization (ICH), Validation of Analytical Procedures: Text and Methodology, Q2 (R1), 2005.

19. Association of Oficial Analytical Chemists (AOAC), Official Methods of Analysis, 20 ed. Washington, DC. 2016.

20. Brazil. Agência Nacional de Vigilância Sanitária. 2017. Resolução RDC n 166 de 27 de julho de 2017. Dispõe sobre a validação de métodos analíticos e dá outras providências, Diário Oficial da União: Brasília.

21. Singh S, Junwal M, Modhe G, Tiwari H, Kurmi M, Parashar N, Sidduri, P. Forced degradation studies to assess the stability of drugs and products. Trends in Analytical Chemistry. 2013, 49: 71-88.

22. Plackett RL, Burman JP. The design of optimum multifactorial experiments. Biometrika. 1946, 33(4): 305-325

23. Youden WJ, Steiner EH. Statistical Manual of AOAC - Association of Official Analytical Chemistry. Washington, DC, 1975.

24. Singh S, Gadhawala Z. Development of a stability indicating RP-RRLC method for determination of allopurinol and its degradation products in solid oral 
dosage. Inter J Pharm Tech Research. 2013, 5(1): 4453.

25. Sajan PG, Rohith T, Patil S, Mantelingu K, Rangappa, KS, Kumara MN. A validated stability indicating RPUPLC method for the quantitative determination of potential impurities of allopurinol. Amer J Pharm Health Research. 2014, 2(10).

26. Tian T, Yang M, Zhao Z, Luan Y, Tang X, Zhu M, Liu $Y$. Development and validation of stability-indicating method for the simultaneous determination of ketoconazole and beauvericin in pharmaceutical tablets. J Chrom Sci. 2016; 54(3): 361-366.

27. Mhaske RA, Sahasrabudhe S. Identification of major degradation products of ketoconazole. Sci Pharm. 2011, 79: 817-836.

28. Duque MD, Souza, DH, Gonçalves LM, Bernardo RS, Pinho JJRG. Avaliação das propriedades físicoquímicas de preparações farmacêuticas contendo cetoconazol para uso tópico. HU Revista. 2013, 39(3,4): 45-49.

29. Staub I, Flores L, Gosmann G, Pohlmann A, Fröehlich PE, Schapoval ES, Bergold AM. Photostability studies of ketoconazole: isolation and structural elucidation of the main photodegradation products. Latin Amer J Pharmacy. 2010, 29(7): 1100-1106.

30. Mendonça CC, Rodrigues KA, Campos, MAL, Medeiros MCM, Casteli VC, Ferrari M, Musis CR, Machado SRP. Emulsões O/A contendo cetoconazol 2,0\%: avaliação da estabilidade acelerada e estudos de liberação in vitro. R Ci Farm Básica. 2009, 30(1): 35 46.

31. Staub, I; Cruz, AS; Pinto, TJA; Schapoval, EES; Bergold, AM. Determinação da segurança biológica do xampu de cetoconazol: teste de irritação ocular e avaliação do potencial de citotoxicidade in vitro. $\mathrm{R}$ Bras Ci Farm, 2007, 43(2). 